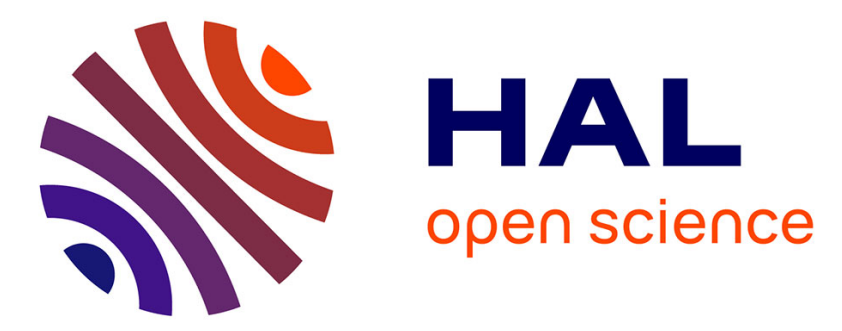

\title{
LOW TEMPERATURE PHASE TRANSITIONS IN THE HEAVY ELECTRON COMPOUND YbSb
}

P. Bonville, Jean-Marc Broto, A. Fert, F. Gonzalez-Jimenez, A. Hamzic, F. Hulliger, P. Imbert, G. Jehanno, J. B. Marimon da Cunha, M. Miljak, et al.

\section{- To cite this version:}

P. Bonville, Jean-Marc Broto, A. Fert, F. Gonzalez-Jimenez, A. Hamzic, et al.. LOW TEMPERATURE PHASE TRANSITIONS IN THE HEAVY ELECTRON COMPOUND YbSb. Journal de Physique Colloques, 1988, 49 (C8), pp.C8-727-C8-728. 10.1051/jphyscol:19888330 . jpa-00228506

\section{HAL Id: jpa-00228506 https://hal.science/jpa-00228506}

Submitted on 1 Jan 1988

HAL is a multi-disciplinary open access archive for the deposit and dissemination of scientific research documents, whether they are published or not. The documents may come from teaching and research institutions in France or abroad, or from public or private research centers.
L'archive ouverte pluridisciplinaire HAL, est destinée au dépôt et à la diffusion de documents scientifiques de niveau recherche, publiés ou non, émanant des établissements d'enseignement et de recherche français ou étrangers, des laboratoires publics ou privés. 


\title{
LOW TEMPERATURE PHASE TRANSITIONS IN THE HEAVY ELECTRON COMPOUND YbSb
}

\author{
P. Bonville $\left({ }^{1}\right)$, J. M. Broto $\left({ }^{2}\right)$, A. Fert $\left({ }^{2}\right)$, F. Gonzalez-Jimenez $\left({ }^{2}\right)^{1}$, A. Hamzic $\left({ }^{4}\right)$, F. Hulliger $\left({ }^{5}\right)$, \\ P. Imbert $\left({ }^{1}\right)$, G. Jehanno $\left({ }^{1}\right)$, J. B. Marimon da Cunha $\left({ }^{1}\right)^{2}$, M. Miljak $\left({ }^{4}\right)$ and H. R. Ott $\left({ }^{3}\right)$ \\ ${ }^{1}$ ) DPhG/PSRM, CEN Saclay, 91191 Gif-sur-Yvette Cedex, France \\ ( $\left.{ }^{2}\right)$ Lab. Phys. des Solides, Univ. Paris-Sud, 91405 Orsay, France \\ (3) Lab. Für Festkörperphys., ETH-Hönggerberg, 8093 Zürich, Switzerland \\ ( $\left.{ }^{4}\right)$ Inst. of Physics, Zagreb University, Yugoslavia
}

\begin{abstract}
Using Mössbauer spectroscopy on ${ }^{170} \mathrm{Yb}$, we detected two low temperature phase transitions in the heavy electron pnictide $\mathrm{YbSb}$. Below $T_{\mathrm{N}}=0.32 \mathrm{~K}$ antiferromagnetic ordering of $\mathrm{Yb}^{3+}$ develops, and between $0.32 \mathrm{~K}$ and $5 \mathrm{~K}$ a phase exists whose nature is yet undetermined. Magneto-transport measurements confirm the heavy electron properties and the $5 \mathrm{~K}$ phase transition.
\end{abstract}

The cubic pnictides $\mathrm{YbP}$ and $\mathrm{YbAs}$ are heavy electron materials [1] which show Kondo-frustrated magnetic ordering at very low temperatures $\left(T_{\mathrm{N}} \simeq 0.4 \mathrm{~K}\right.$ and $0.6 \mathrm{~K})[2,3]$. Using Mössbauer absorption spectroscopy on ${ }^{170} \mathrm{Yb}\left(I_{\mathrm{E}}=2, I_{\mathrm{G}}=0, E=84 \mathrm{keV}\right)$ we investigated the isoelectronic compound $\mathrm{YbSb}$ and we found that it undergoes two phase transitions, at $5 \mathrm{~K}$ and at $0.32 \mathrm{~K}$. The $5 \mathrm{~K}$ phase transition was confirmed by magneto-transport measurements.

\section{Observation of antiferromagnetic ordering in $\mathbf{Y b S b}$}

The Mössbauer spectrum at $T=0.045 \mathrm{~K}$ in zero external field is a poorly resolved five line hyperfine spectrum due to a magnetic hyperfine field of $63 \mathrm{~T}$. This demonstrates the presence of a spontaneous $\mathrm{Yb}^{3+}$ moment of $0.63 \mu_{\mathrm{B}}$, i.e. of magnetic ordering of the $\mathrm{Yb}^{3+}$ ions. The hyperfine field remains constant up to $0.2 \mathrm{~K}$, and then decreases to $50 \mathrm{~T}$ at $0.3 \mathrm{~K}$; by extrapolation we estimate that the magnetic transition occurs at $(0.32 \pm 0.02) \mathrm{K}$. Spectra were taken with an external magnetic field $H_{\text {ext }}$ of $5.8 \mathrm{~T}$ parallel to the direction of propagation of the $\gamma$-rays; they are shown in figure 1. At $T=0.045 \mathrm{~K}$ (Fig. 1a) the angle $\varphi=\left(\mathbf{H}_{\text {ext }}, \mathbf{H}_{\mathrm{hf}}\right)$ obtained is close to $70^{\circ}$ as in $\mathrm{YbAs}$ [3] and the hyperfine field is $72 \mathrm{~T}$. This indicates that the magnetic structure has first rotated towards a direction almost perpendicular to $\mathbf{H}_{\text {ext }}$ when applying the external magnetic field, i.e. that the spontaneous structure is antiferromagnetic. In a simple model assuming two magnetic sublattices [3], one can estimate the exchange field by: $H_{\text {exch }}=H_{\text {ext }} / 2 \cos \varphi \simeq 8 \mathrm{~T}$. The magnetic moment derived from the $H_{\mathrm{hf}}$ value is $0.72 \mu_{\mathrm{B}}$, about $10 \%$ bigger than its value in zero external field.

\footnotetext{
${ }^{1}$ On leave from Dept. de Fisica, U.C.V., Caracas, Venezuela.

${ }^{2}$ On leave from U.F.R.G.S., Porto-Alegre, Brasil.
}

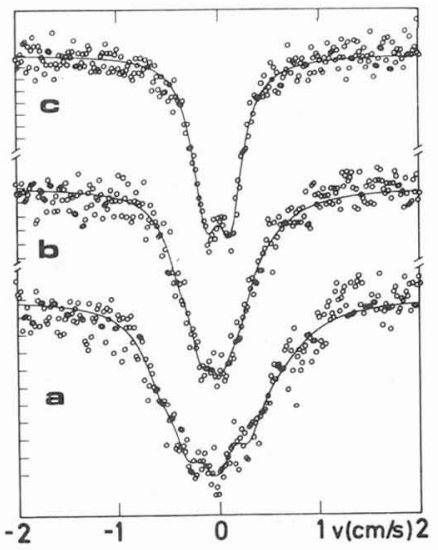

Fig. 1.- Mössbauer spectra in YbSb with an external magnetic field of $5.8 \mathrm{~T}$ : (a) $T=0.045 \mathrm{~K}$; (b) $T=1.4 \mathrm{~K}$; (c) $T=10 \mathrm{~K}$.

These features are characteristic of a Kondofrustrated magnetic ordering very similar to that observed in YbP [2] and YbAs [3]: the mean value of the spontaneous saturated electronic moment, $0.66 \mu_{\mathrm{B}}$, is reduced with respect to that of any of the possible crystal field ground-states of $\mathrm{Yb}^{3+}$ in cubic symmetry: $\Gamma_{7}\left(1.72 \mu_{\mathrm{B}}\right), \Gamma_{6}\left(1.33 \mu_{\mathrm{B}}\right)$ or $\Gamma_{8}\left(2.1 \mu_{\mathrm{B}}\right)$; the value of $T_{\mathrm{N}}(0.32 \mathrm{~K})$ is much lower than the exchange energy

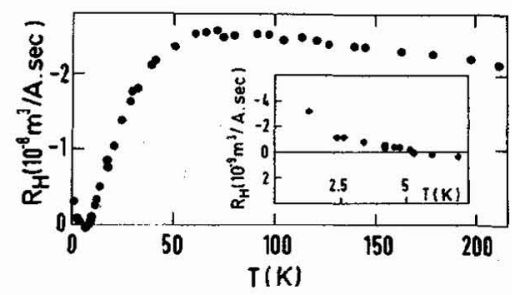

Fig. 2. - Thermal variation of the initial Hall constant $\boldsymbol{R}_{\mathrm{H}}$ (measured for $H<0.1 \mathrm{~T}$ ). 
$\mu_{\mathrm{B}} H_{\text {exch }} \simeq 10 \mathrm{~K}$; finally, the enhancement of the saturated electronic moment under external field reflects the fact that the Kondo compensation is partially destroyed by a magnetic field. $\mathrm{YbSb}$ is then a magnetic heavy electron material.

\section{Observation of a second phase transition in $\mathbf{Y b S b}$}

Between $0.4 \mathrm{~K}$ and $4.2 \mathrm{~K}$, the Mössbauer spectrum consists of an unresolved broad line (FWHM $\simeq 7 \mathrm{~mm} / \mathrm{s}$ ) with a slight asymmetry; above $5 \mathrm{~K}$ the spectrum is a narrow line ( $\mathrm{FWHM}=3 \mathrm{~mm} / \mathrm{s}$ ). As shown in the inset of figure 3 , the linewidth changes abruptly between $4 \mathrm{~K}$ and $5 \mathrm{~K}$, which strongly suggests the existence of a phase transition at $T_{\mathrm{t}} \simeq 5 \mathrm{~K}$. The lack of resolution of the zero field spectra between $0.4 \mathrm{~K}$ and $4.2 \mathrm{~K}$ makes it difficult to fit them in an unambiguous way: a pure quadrupolar hyperfine interaction accounts well for the lineshape (suggesting a structural and/or an electronic quadrupolar transition), as does a magnetic hyperfine interaction corresponding to an electronic moment of ca. $0.4 \mu_{\mathrm{B}}$ (implying a magnetic transition to a phase that might present a complicated structure as observed in CeSb [4]). Measurements with an external field of $5.8 \mathrm{~T}$ provide some additional information. The spectrum at $10 \mathrm{~K}$ (Fig. 1c) is a 2-line spectrum, which means that $\varphi=0$, i.e. the external field has aligned the induced paramagnetic moments $\left(0.26 \mu_{\mathrm{B}}\right)$ along its direction. On the contrary, the $1.4 \mathrm{~K}$ spectrum (Fig. 1b) shows that the angle $\varphi$ is non zero in the intermediate phase: the best fit yields $\varphi=76^{\circ}$ and $H_{\mathrm{hf}}=39.4 \mathrm{~T}\left(\mu=0.39 \mu_{\mathrm{B}}\right)$.

This demonstrates that there exists an antiferromagnetic coupling between $\mathrm{Yb}^{3+}$ moments in this phase. But this fact does not necessarily imply that the zero field intermediate phase is magnetically ordered. We recall that in $\mathrm{CeB}_{6}$, observation of an antiferromag-

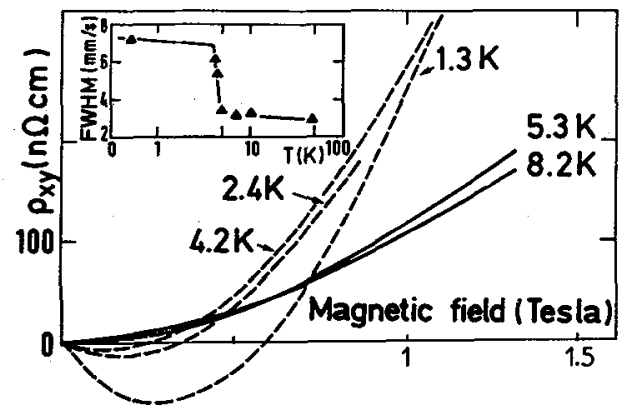

Fig. 3. - Hall resistivity $\rho_{x y}$ versus magnetic field at various temperatures. The inset shows the thermal variation of the Mössbauer linewidth (the line is a guide to the eye). netic structure induced by an external magnetic field has been assigned to an antiferroquadrupolar ordering of the $\mathrm{Ce}^{3+}$ ions in zero magnetic field [5].

\section{Magneto-transport measurements in YbSb}

Resistivity, Hall constant and magneto-resistance measurements have been performed on polycrystals in fields up to $6 \mathrm{~T}$ between $1.3 \mathrm{~K}$ and $300 \mathrm{~K}$. The temperature dependence of the magnetic resistivity and of the initial Hall constant $R_{H}$ are typical of heavy electron systems. We reserve a more detailed study of the resistivity for a longer publication and we present only the results concerning the initial Hall constant $R_{\mathrm{H}}$ (measured in the range $H<0.1 \mathrm{~T}$ where the Hall resistivity is linear in $H$ ) displayed in figure $2: R_{\mathrm{H}}$ presents a maximum at about $60 \mathrm{~K}$ and, below $60 \mathrm{~K}$, drops rapidly as expected for Kondo lattice systems below the onset temperature for coherence. The magnetoresistance ratio $[\rho(H)-\rho(H=0)] / \rho(H=0)$ is close to 1 , which is much bigger than in normal metals. In figure 3 we show the field dependence of the Hall resistivity $\rho_{x y}$ for various temperatures in the range $1.3 \mathrm{~K}-8.2 \mathrm{~K}$. The transition at $5 \mathrm{~K}$ is inferred by the drastic change of the $\rho_{x y}(H)$ curve between $4.2 \mathrm{~K}$ and $5.3 \mathrm{~K}$. In particular, the sign of the initial Hall constant changes at about $5.1 \mathrm{~K}$, as shown in the inset of figure 2 .

In conclusion we observed two low temperature phase transitions in $\mathrm{YbSb}$. Below $T_{\mathrm{N}}=0.32 \mathrm{~K}$, a Kondo-frustrated antiferromagnetic ordering of the $\mathrm{Yb}^{3+}$ ions sets in. In the region $0.32 \mathrm{~K}<T<5 \mathrm{~K}$, YbSb presents a phase which shows a canted antiferromagnetic structure in the presence of an external magnetic field; this could be due to either antiferromagnetic or antiferroquadrupolar spontaneous ordering.

[1] Ott, H. R., Rudigier, H., Hulliger, F., Solid State Commun. 55 (1985) 113.

[2] Bonville, P., Hodges, J. A., Hulliger, F., Imbert, P., Ott, H. R., J. Magn. Magn. Mater. 63 \& 64 (1987) 626.

[3] Bonville, P., Hodges, J. A., Hulliger, F., Imbert, P., Jehanno, G., Marimon da Cunha, J. B., Ott, H. R., Hyperfine Interactions 40 (1988) 381.

[4] Fischer, P., Lebech, B., Meier, G., Rainford, B. D., Vogt, O., J. Phys. C 11 (1978) 345.

[5] Effantin, J. M., Rossat-Mignot, J., Burlet, P., Bartholin, H., Kunii, S., Kasuya, T., J. Magn. Magn. Mater. $47 \& 48$ (1985) 145. 